\title{
STRUCTURAL AND OPTICAL PROPERTIES OF CdO THIN FILMS
}

\section{DEPOSITED BY SPRAY PYROLYSIS TECHNIQUE.}

\section{R.S. Meshram ${ }^{1}$, R.M. Thombre ${ }^{2}$}

1 Nevjabai Hitkarini College, Bramhapuri, Dist. Chandrapur (M.S.), India.

2 Mahatma Gandhi College, Armori, Dist. Gadchiroli Email-meshramratan@gmail.com

\begin{abstract}
:-
Cadmium Oxide [CdO]films were deposited on glass Substrate by Spray Pyrolysis. Transparent and Conducting $\mathrm{CdO}$ films prepared at $300^{\circ} \mathrm{C}$ temperature. The optical band gap of the $\mathrm{CdO}$ films deposited at $300^{\circ} \mathrm{C}$ was estimated and found to vary from $2.24 \mathrm{eV}-2.49 \mathrm{eV}$. X-ray diffraction (XRD) studies indicate the formation of polycrystalline cubic CdO phase. Scanning Electron Microscopy (SEM) shows that the films prepared at $300^{\circ} \mathrm{C}$ consists of spherical shape grains with size in nanometer range. UV-VIS spectrum of the films showed that the optical band energy increases with concentration of Cadmium Chloride in the solution.
\end{abstract}

Keywords:CdO thin films, XRD, SEM, Band gap, Structural, Optical properties.

\section{Introduction:-}

Transparent conductive oxides (TCOs), an attracting type of Semiconducting materials that are both optically transparent and electrical conductive, have potential application in Optoelectronic devices such as solar cells, photovoltaic, flat panel displays, transparent electrodes, Ohmic contact to LEDs, and heat reflectors [1-4]. In recent years CdO- based TCOs (binary semiconducting Oxides, received much attention due to their exceptional carrier mobility, nearly metallic conductivities and simple crystal structure [5]. Many techniques were adopted to glow $\mathrm{CdO}$ films such as : thermal evaporation [6], metal vapaur organic deposition [7], Spray Pyrolysis [5], rapid photothermal oxidation of cd [8] and pulsed laser deposition [9-10].

During the last few years thin films of Cadmium Oxide (CdO) has revealed itself as a very promising material for use in photovoltaic 
industry. Because of its high electrical conductivity, high optical transparency in the spectral region of sun radiation[11].

$\mathrm{CdO}$ has a direct optical energy bandgap of $2.45 \mathrm{ev}$ and the electrical properties can suitably controlled by altering the deposition conditions[12].

$\mathrm{CdO}$ belongs to the family of transparent conducting Oxide films whose extremely wide range of physical and chemical properties makes them important materials both for technological and industrial applications[13].

Spray Pyrolysis technique (Chopra et at 1982) has been used for several decades in glass industry and in solar cell production to deposit electrically conducting electrodes. Thin films formation using this techniques involves spraying a metal salt solution onto a heated substrate. The sprayed droplet reacting the hot substrate surface undergoes pyrolytic decomposition and forms the desired product[14].

\section{Experimental:}

Spray Pyrolysis is basically a chemical process involves spraying aqueous solution onto a substrate held at high temperature, where the substrate provides the thermal energy for the thermal decomposition and subsequent recombination of the constitutent species followed by sintering and recrystallization of the clusters of crystallite giving rise to a coherent films. A simply glass nozzle was fabricated to give a fine and very small droplets of solution which is driven by air from the compressor. The solution was prepared by dissolving a known quantity of Cadmium Chloride in deionised water[13].

Cadmium Oxide thin films have been deposited on glass substrate from aqueous solution of Cadmium Chloride $\mathrm{CdCl} 2$. In concentration range from $0.01 \mathrm{M}, \quad 0.025 \mathrm{M} \& \quad 0.05 \mathrm{M}$ using Spray Pyrolysis technique[14].

The crystalline structures and the surface morphologies of the deposited films were investigated by using X-ray diffraction (XRD) and 
scanning electro microscopy (SEM). The optical transmission and the absorption for the sample were measured with a UV-VIS spectrophotometer[15].

\section{Result and Discussion}

\section{Structural Properties:-}

The X-ray diffraction (XRD) pattern of the CdO thin films was shown in the fig. 1 The presence of Several peaks in the XRD pattern reveals that the films are polycrystalline. The structure was found to be cubic.

The average grain Size (g) of the polycrystalline material can be calculated from the X-ray spectrum by means of full width at half maximum (FWHM) method (Scherrer relation) [13]:

$$
g=\frac{0.94 \lambda}{\left[\Delta_{(2 \theta)} \operatorname{COS} \theta\right]} \ldots \ldots \ldots \ldots
$$

Where,

$\lambda$ : is the $\mathrm{X}$-ray wavelenghth $\left(\mathrm{A}^{\circ}\right)$

$\Delta_{(2 \theta)}:$ FWHM (radian)

$\theta$ : Bragg diffraction angle of the XRD peaks (degree)

Where $\Delta \theta$ is the full width at half maximum of the XRD peaks appearing at the diffraction angle $\theta$, A represents the shape factor.The grain size (g) was found to be $315 \mathrm{~nm} \& 352 \mathrm{~nm}$.

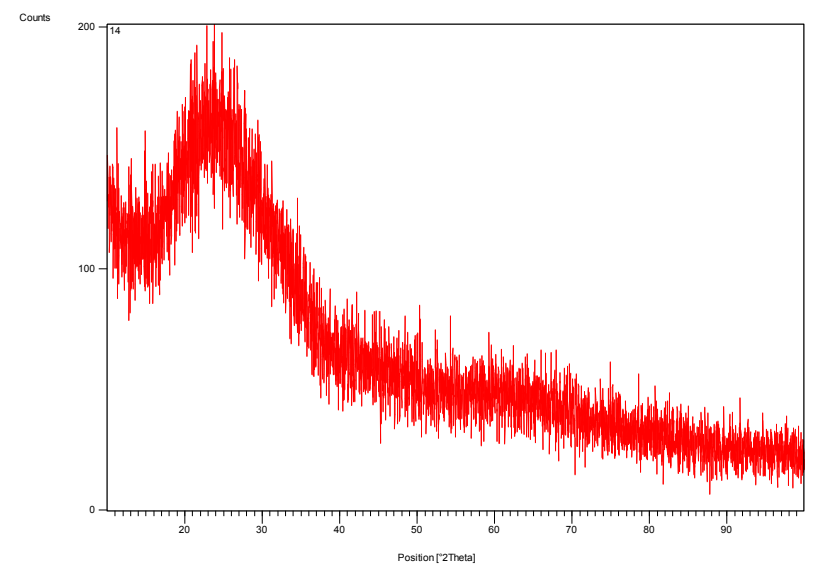

Fig $1 \mathrm{X}$-ray diffraction pattern of sprayed CdO film at substrate temperature, $300^{\circ} \mathrm{C}$ 


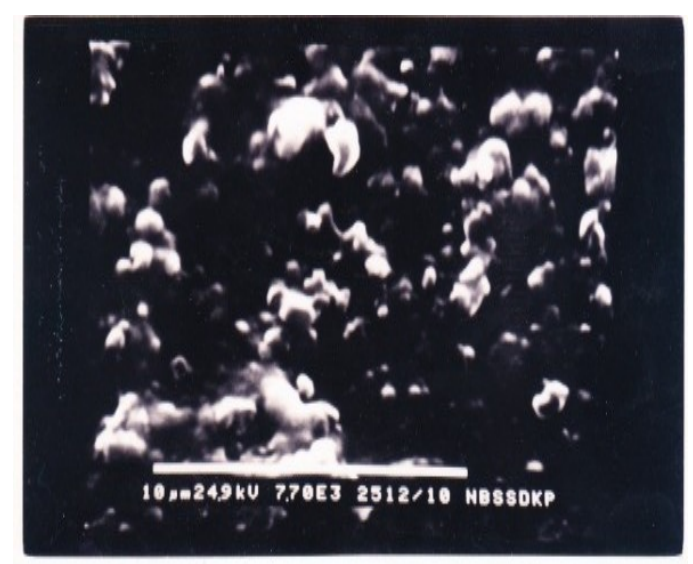

Fig 2 Scanning Electron microscopy as deposited $\mathrm{CdO}$ on glass substrate at, $300^{\circ} \mathrm{C}$ sprayed

Optical Properties :The Optical absorption in the UV region is dominated by the optical band gap of the semiconductor. The optical band gap (Eg) of a semiconductor is related to the optical absorption coefficient $(\alpha)$ and the incident Photon energy $(\mathrm{hu})$ by $[12,13]$

$$
(\alpha h v)=(\text { Eg- hv })^{\mathrm{n}} \text {, }
$$

Where $\mathrm{n}$ depends on the kind of optical transition that prevails specifically, $\mathrm{n}$ is $1 / 2$ and 2 when the transition is directly and indirectly allowed, respectively. The CdO films are known to be a semiconductor with a directly allowed transition, and its optical band gap can be obtained by plotting the optical absorption verses the photon energy and extrapolating the linear portion of the curve to $(\alpha h v)^{2}=0$. The optical band gap of the $\mathrm{CdO}$ films prepared at a substrate temperature $300^{\circ} \mathrm{C}$ was $2.24 \mathrm{eV}, 2.35 \mathrm{eV} \& 2.49 \mathrm{eV}$ as shown in fig $7 \mathrm{a}, 7 \mathrm{~b} \& 7 \mathrm{c}$. This is in good agreement with the previously reported values of $2.4 \mathrm{ev}$ and $2.42 \mathrm{eV}$ $[14,15]$. 


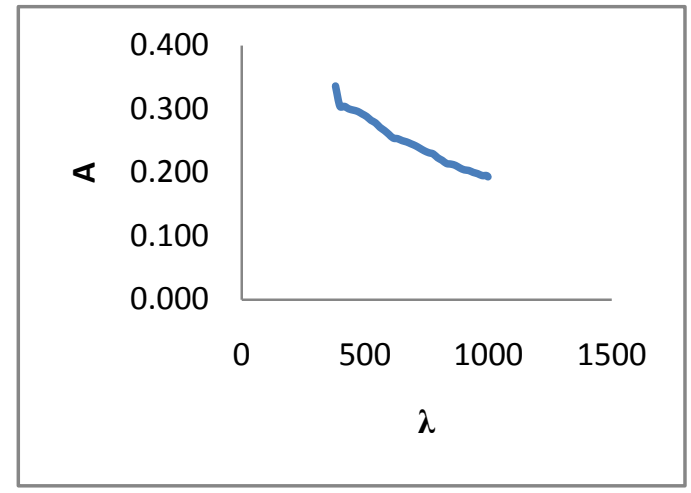

Fig : $3 a$ The absorption spectra of $\mathrm{CdO}$ thin Film as a function to wavelength thickness, $\mathrm{t}=0.4170 \mu \mathrm{m}$

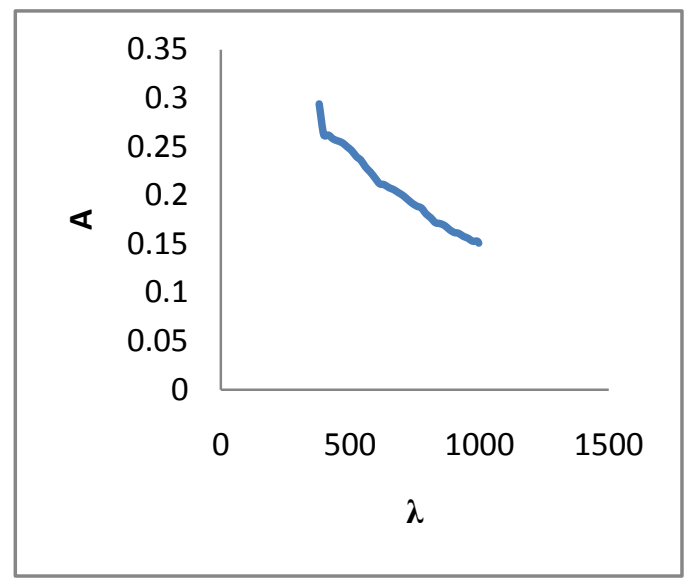

Fig: $3 b$ The absorption spectra of $\mathrm{CdO}$ thin Film as a function to wavelength thickness, $\mathrm{t}=0.4391 \mu \mathrm{m}$

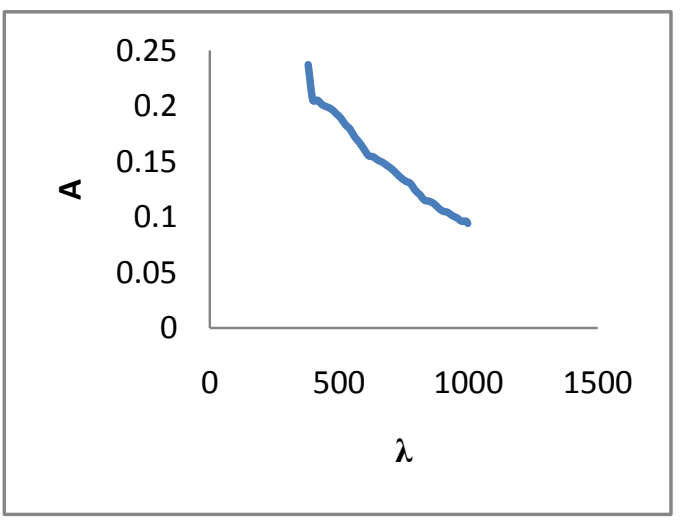

Fig: 3c The absorption spectra of CdO thin Film as a function to wavelength thickness, $\mathrm{t}=0.5248 \mu \mathrm{m}$

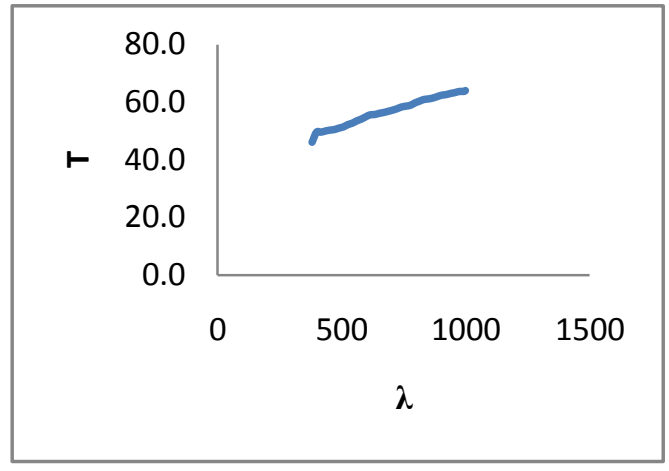

Fig :4a The transmission spectra of CdO thin Film as a function to wavelength thickness, $\mathrm{t}=0.4170$ $\mu \mathrm{m}$

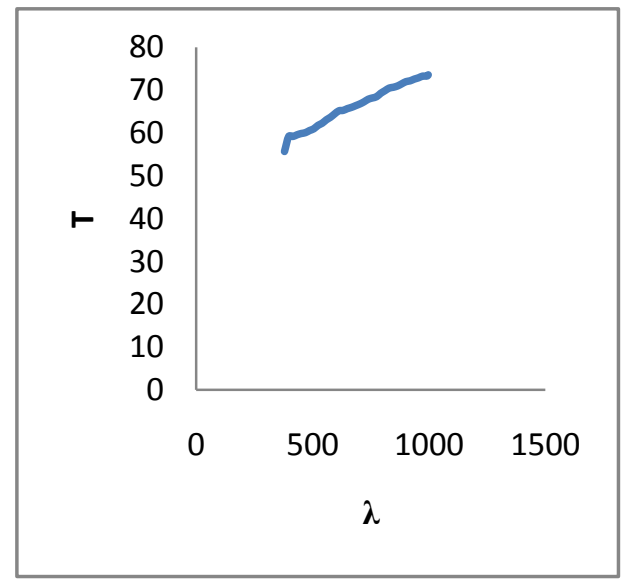

Fig: $4 \mathrm{~b}$ The transmission spectra of $\mathrm{CdO}$ thin Film as a function to wavelength thickness, $\mathrm{t}=0.4391 \mu \mathrm{m}$

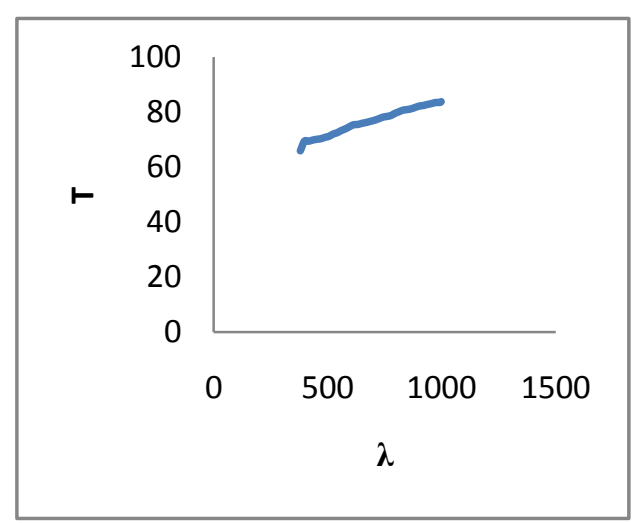

Fig: 4c The transmission spectra of CdO thin Film as a function to wavelength thickness, $\mathrm{t}=0.5248 \mu \mathrm{m}$ 


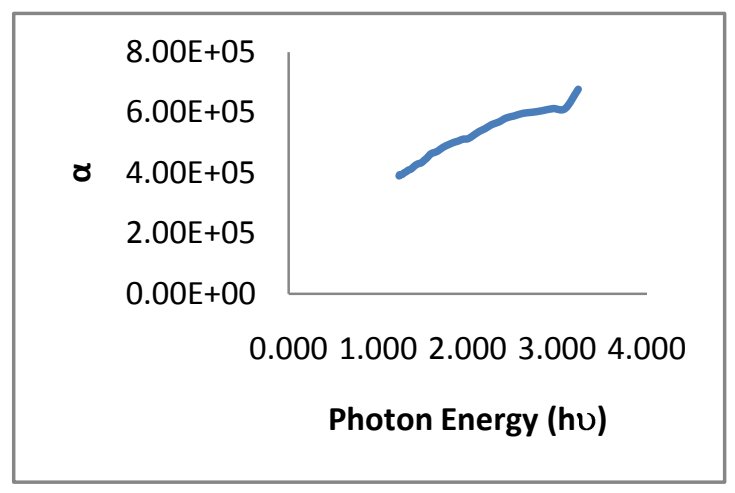

Fig:5a The absorption Coefficient of $\mathrm{CdO}$ thin Film as a function to photon energy, thickness, $\mathrm{t}=0.4170 \mu \mathrm{m}$

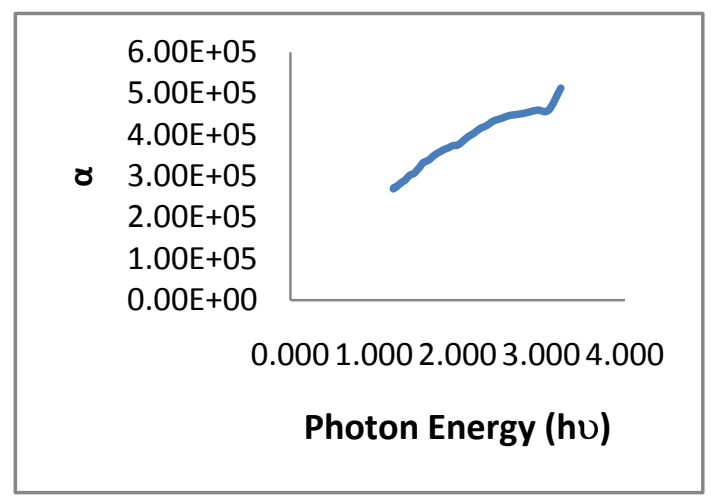

Fig: $5 b$ The absorption Coefficient of $\mathrm{CdO}$ thin Film as a function to photon energy, thickness, $t=0.4391 \mu \mathrm{m}$

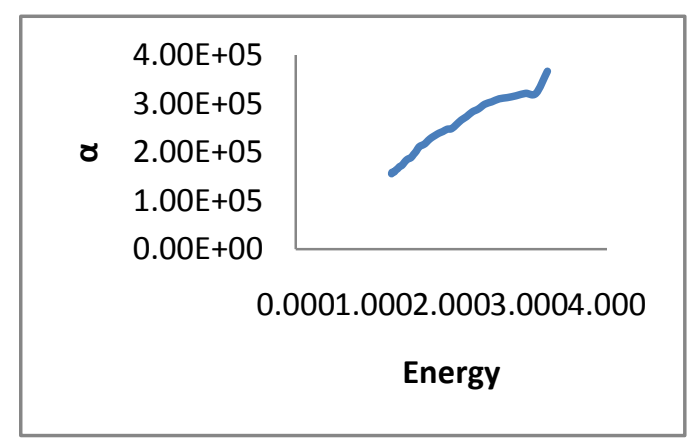

Fig: 5cThe absorption Coefficient of $\mathrm{CdO}$ thin Film as a function to photon energy, thickness, $\mathrm{t}=0.5248 \mu \mathrm{m}$

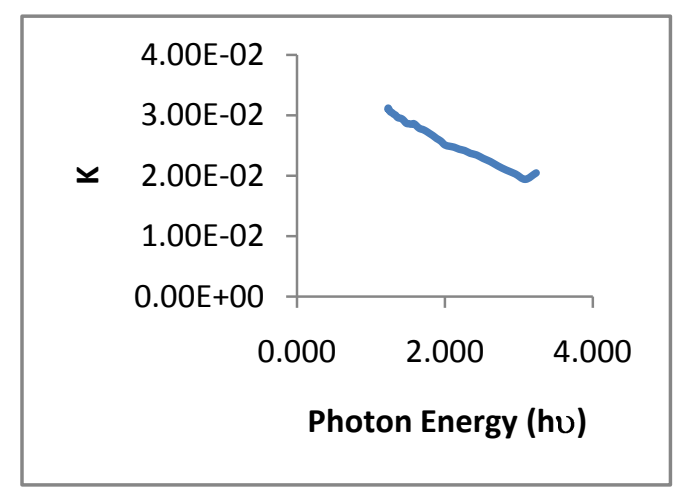

Fig:6a The extinction Coefficient of $\mathrm{CdO}$ thin Film as a function to photon energy, thickness, $t=0.4170 \mu \mathrm{m}$

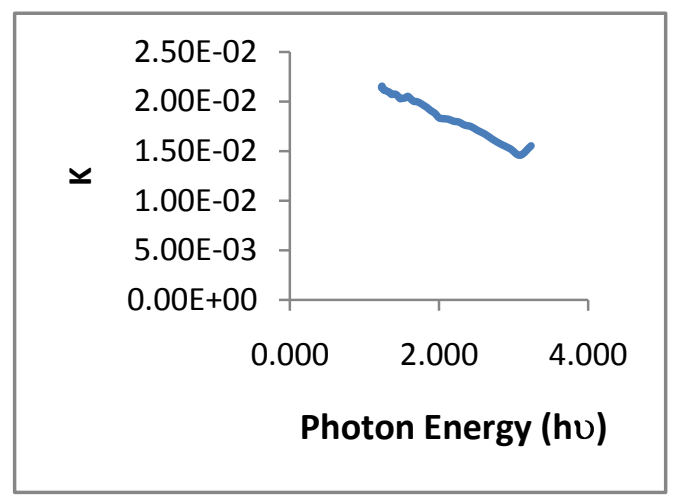

Fig: $6 \mathrm{~b}$ The extinction Coefficient of $\mathrm{CdO}$ thin Film as a function to photon energy, thickness, $\mathrm{t}=0.4391 \mu \mathrm{m}$

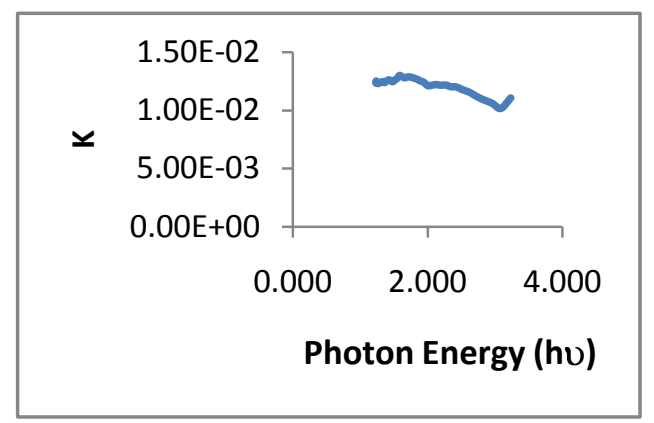

Fig: $6 \mathrm{c}$ The extinction Coefficient of $\mathrm{CdO}$ thin Film as a function to photon energy, thickness, $\mathrm{t}=0.5248 \mu \mathrm{m}$ 


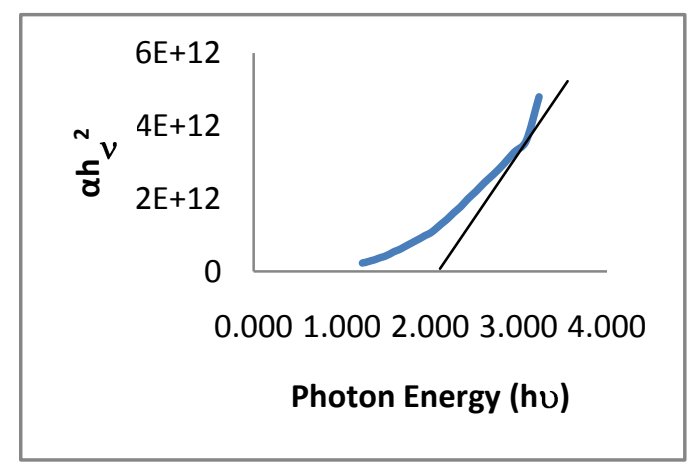

Fig:7a The optical energy gap for the direct allow

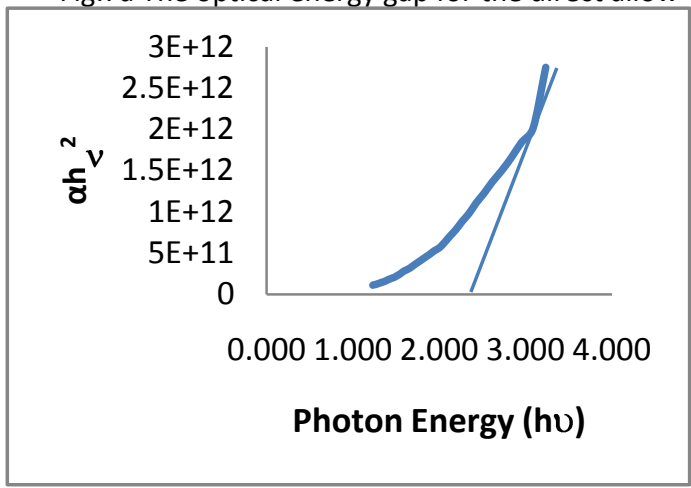

Fig: 7b The optical energy gap for the direct allow transition of $\mathrm{CdO}$ thin Film thickness, $\mathrm{t}=0.4391 \mu \mathrm{m}$

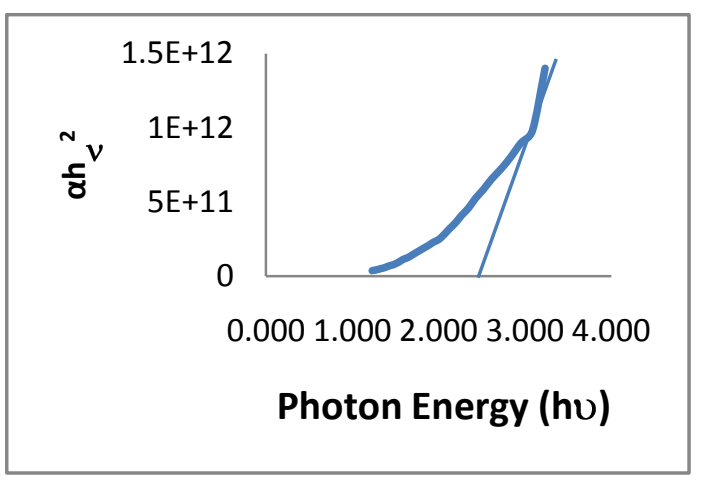

Fig:7c The optical energy gap for the direct allow transition of $\mathrm{CdO}$ thin Film thickness, $\mathrm{t}=0.5248 \mu \mathrm{m}$

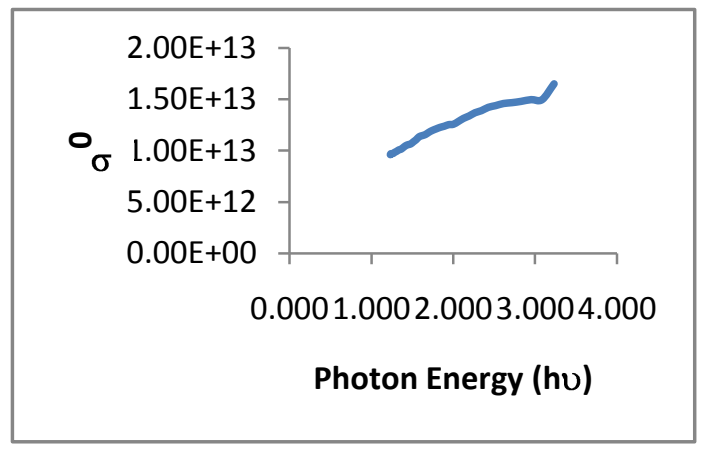

Fig: 8a The optical conductivity of $\mathrm{CdO}$ thin Film as a function to the photon energy, thickness, $\mathrm{t}=0.4170 \mu \mathrm{m}$

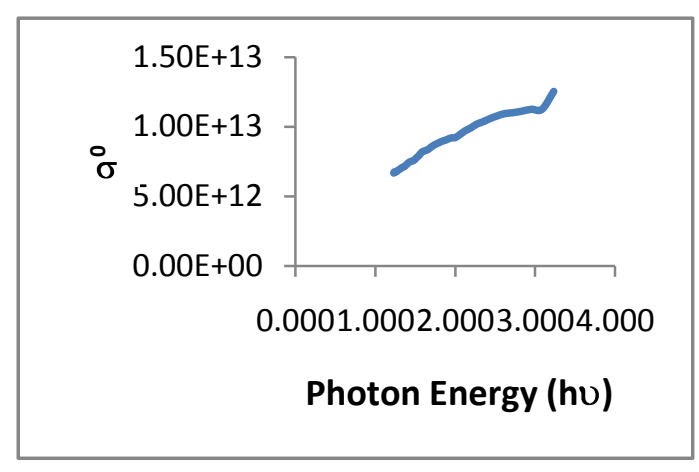

Fig:8b The optical conductivity of $\mathrm{CdO}$ thin Film as a function to the photon energy, thickness, $t=0.4391 \mu \mathrm{m}$

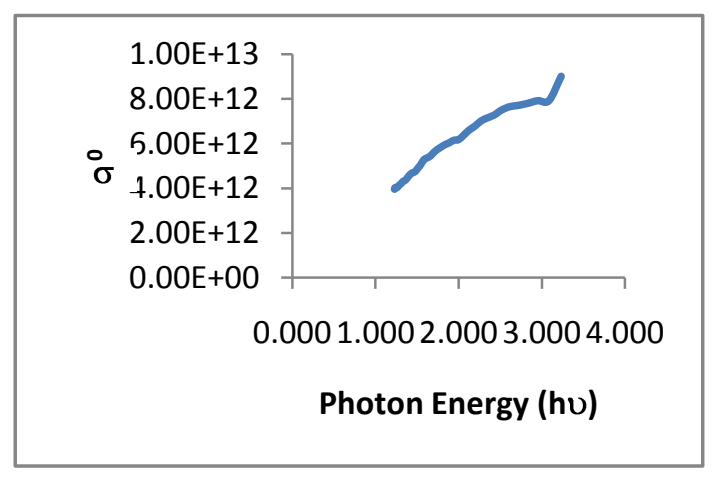

Fig: 8c The optical conductivity of $\mathrm{CdO}$ thin Film as a function to the photon energy, thickness, $t=0.5248 \mu \mathrm{m}$ 


\section{Conclusion :}

$\mathrm{CdO}$ thin films have been prepared from different molar concentrations of Cadmium Chloride onto glass substrate keeping the substrate temperature $300^{\circ} \mathrm{C}$ using a simple Spray Pyrolysis method. Optical and structural properties have been studied with the variation of molar concentration $[0.01 \mathrm{M}, 0.025 \mathrm{M}, 0.05 \mathrm{M}]$, the thickness of the deposited thin films changes from $0.4170 \mu \mathrm{m}-0.5248 \mu \mathrm{m}$

The SEM micrograph of as deposited films show homogenous deposition over the substrate. SEM micrographs exhibit clear grains and gain boundary formation. It is observed that the band gap decreases with the increase of the molar concentrations of the Cadmium Chloride aqueous solution. The optical band gap was found to vary from $2.24 \mathrm{eV}$ $2.49 \mathrm{eV}$. These results are in good agreement with other reported values.

\section{References :-}

Ramakrishna, K.T. Reddy, Shanthini G.M., Johnston D., and Miles R.W. (2003), Highly transparent and conducting CdO films grown by Chemical Spray Pyrolysis. Thin solid films by Elsevier Science B.V., U.S.A. P: 427, 397

Dhage, S; Ravi, V. and Date, S.Bull. (2004). Mater . Sci. by Elsevier Science B.V., U.S.A. (2ed) p: 27, 43.

Coutts, T.J.; Young, D.L. X. Li. ; Mulligan, W.P. and Wu, X. (2000). J. Vac. Sci. Technol by Elsevier Science B.V., U.S.A., A 18, 2646.

Shim, T.; Ma, D. (2002). Thin Solid Films. By Elsevier Science B.V. U.S.A. 8,410

Deokate, R.J.; Pawar, S.M. Moholkar, A.V.; Sawant, V.S. and Pawar C.A. (2008), Spray deposition of highly transparent fluorine doped CdO thin films. Appl. Surf. Sci. by Johan Wiley \& Sons Ltd. New York, $254(7): 2187$. 
Dakhel, A.A. and Henari, F.Z. (2003), "Optical characterization of thermally evaporated thin"CdO films. Cryst. Res. Technol by WilyVCH GmbH \& Co. KGaA, Bahrain, 38 (11) : 979-985.

Mane, R.S.: Pathan, H.M.; Lokhande, C.D. and Han, S-H. (2006). Sol. Energy by Johan Wiley \& Sons Ltd, New York, 80, P:185

Ismail, R.; Abeduarazak, O (2007) Sol. Energy Mater. Sol. Cells, by Springer Science + Business Media, LLC., 91 p: 903.

Islam M.M. Islam M.R. and Podder J. (2008). "Optical and electrical characteristics of $\mathrm{CdO}$ thin films deposited by Spray Pyrolysis method". Journal of Bangladesh Academy of Science. Dhaka, Bangladesh 32 (1) : 97-105.

S.A. Maki and M.Q. Mustafa, Effect of Annealing Temperature on the structural and optical properties of the $\mathrm{CdO}$ thin films Prepared By Vacuum Evaporation Thermal Technique, Ibn Al-Haitham Journal for Pure and Applied Science No.1, Vol. 25, Year 2012.

Peter Christov Shindov, CdO THIN FILMS DEPOSITED BY SPRAY PYROLYSIS, ELECTRONICS, 2004

K.T. Ramakrishna Reddy, G.M. Shanthini, D. Johnston, R.W. Miles, Highly transparent and conducting $\mathrm{CdO}$ films gorwn by Chemical Spray Pyrolysis, thin solid films 427(2003) 397-400.

M.M. ISLAM, J. PODDER, M.R. ISLAM, effect of molar concentration on the optical and surface properties of CdO thin film deposited by Spray Pyrolysis, OPTOELECRONICS AND ADVANCED RAPID COMMUNICATION Vol. 4, No. 7, July 2010, p.968-972.

B.G. JEYAPRAKASH, K. KESAVAN, R. ASHOK KUMAR, S MOHAN and A AMALARANI, Temperature dependent grain-size and microstrain of CdO thin films prepared by spray pyrolysis method, Bull Mater Sci., Vol. 34, No. 4, July 2011, 99. 601-605.

Dong Ju SEO, structural and optical properties of CdO Films deposited by spray pyrolysis. Journal of the Korean Physical Society, Vol. 45, No. 6, December 2004, pp. 1575-1579. 